\title{
The Design Principles Database as Means for Promoting Design-Based Research
}

Yael Kali, Technion - Israel Institute of Technology

\section{Abstract}

The emergent design-based research (DBR) paradigm is often criticized for having unclear methodologies for warranting claims. This paper proposes a mechanism - the Design Principles Database, which can augment claims made via DBR studies, by enabling researchers to systematically connect these claims to a network of other DBR studies. The potential of the Design Principles Database to support DBR is illustrated by analysis of a particular DBR study focused on peer-evaluation. The analysis shows three phases in which the Design Principles Database supported the researchers in the process of conducting the peer-evaluation study. In the first phase, the researchers articulated design principles based on a literature review and contributed these principles to the database. In the second stage, they designed a peerevaluation activity based on these principles, enacted and revised the peer-evaluation activity in a three-iteration study. In the third phase, they incorporated the lessons they learned through these iterations back to the database. The analysis of this process indicates that the Design Principles Database can contribute to the development of theory on one hand, and to design practice on the other.

Key words: Design based research, Design Principles, Peer-evaluation. 


\section{Introduction}

From its early stages, design based research (DBR) has had the vision to develop into a design-science of education (Collins, 1992), in which critical elements in learning environments are systematically explored in terms of their effect on learning. Herbert Simon (1969) identifies various professions, such as architecture, engineering, computer science, medicine, and education, with the sciences of the artificial, which Collins Joseph, \& Bielaczyc, (2004) refer to as design-sciences. One of the approaches adopted by these fields is to gather and abstract designers' experiences and research, by creating collections of design principles or design patterns that synthesize each of these fields and can guide new designs. Some examples are from the areas of architecture (Alexander, 1977), information science (Tufte, 1983) and computer science (Gamma et al., 1995).

The Design Principles Database, described below (http://design-principles.org), was developed in this spirit, to coalesce and synthesize emerging design knowledge about the use of technologies for education. Kali (in press), illustrates how the Design Principles Database can serve as a collaborative knowledge-building endeavor for the community of the learning sciences. The current chapter focuses on the utility of the database to fill a missing niche in DBR. The chapter commences with a short literature review of methodological challenges in DBR. An approach for conducting DBR is then introduced, which uses the Design Principles Database as means for warranting and generalizing DBR outcomes. A three-phase analysis of the ways researchers used the database in an example-DBR study about peer-evaluation follows 
to demonstrate this approach. Finally, the potential of the Design Principles Database to promote DBR is discussed.

\section{Methodological challenges in design based research}

In order to explore how curricular innovations affect learning in naturalistic settings, more and more researchers tend to adopt the emerging paradigm of DBR. The notion of DBR is very much in vogue in the learning-sciences community, but faces obstacles in the broader research community (Collins et al., 2004). Recently, three major journals have dedicated special issues to illuminate the added value of this methodological niche, as well as discuss challenges still unsolved (Educational Researcher Vol. 32, No.1, 2003; The Journal of the Learning Sciences, Volume 13, No.1, 2004 and Educational Technology, January-February issue, 2005).

Collins et al. (2004) describe "design experiments" (one of the labels referring to early stages of DBR) as follows:

"Design experiments bring together two critical pieces in order to guide us to better educational refinement: a design focus and assessment of critical design elements. Ethnography provides qualitative methods for looking carefully at how a design plays out in practice, and how social and contextual variables interact with cognitive variables. Large-scale studies provide quantitative methods for evaluating the effects of independent variables on the dependent variables. Design experiments are contextualized in educational settings, but with a focus on generalizing from those settings to guide the design process. 
They fill a niche in the array of experimental methods that is needed to improve educational practices.” (p. 21).

However, DBR is still in its infancy stages (Barab \& Squire, 2004; Dede, 2005; The design-based research collective, 2003), and its methodologies are still being challenged (e.g., Kelly, 2004; Shavelson et al., 2003). Questions that doubt DBR methodologies focus around issues of generalization in a field which is contextual in its nature. For instance, Kelly (2004), in his commentary remarks to the JLS special issue about DBR, asks “When one foregoes experimental controls, how can one generalize to other settings regardless of how rich are the local descriptions?” (p.120). Similarly, Shavelson et al., (2003) ask "To what extent would the tool developed in one intensively engineered setting generalize to another setting?” (p. 27)

It is clear that in order to answer such questions, more positivist - reductionst methodologies are required; To be able to generalize that learning, or any other behavior is caused by interaction of students with a technology, and not by any of the vast number of other potential factors involved in naturalistic settings, one is required to reduce all these factors, and design a more controlled study. One approach to bridge between these two methodological polarities, and to earn both the insights gained in naturalistic methods, and the generalizability acquired with more quantitative methods, is to sequence them. As Collins et al. (2004) suggest, DBR can include both formative and summative strategies. While the formative strategies are used to describe lessons learned in successive implementations of an innovation in particular settings, the summative strategies seek to derive at more general conclusions. For example they state that 
“...if we wanted to compare how effective the Waterford and Peabody reading programs are, we would need to carry out comparative analyses in a variety of different settings, such as urban, suburban, and rural schools, and perhaps even homes, workplaces, and military settings. In such studies there must be a fixed experimental procedure, unlike the flexible design revision we recommend for formative evaluation.” (p. 39).

The current study suggests an alternative to the sequencing approach described above for providing warrants for lessons learned by DBR.

\section{The design principles approach}

Successful curriculum materials depend on a process of iterative refinement to respond to the complex system that impacts classroom learning. Emergent designbased research methods suggest ways to capture this process. These methods describe how research teams gather evidence and make decisions about refinements (e.g., Bell, Hoadley, \& Linn, 2004; Linn, Bell, \& Davis, 2004). However, the design knowledge residing in traditional forms of publication is difficult to use for creating new designs. In order to make this knowledge more useful, new approaches for its organization and synthesis are needed. Linn et al. (2004) suggested using design principles as an organization unit. According to this approach, design principles that cut across a variety of designs are synthesized and abstracted based on various DBR projects. Bell et al. (2004), refer to such design principles as: 
“...an intermediate step between scientific findings, which must be generalized and replicable, and local experiences or examples that come up in practice. Because of the need to interpret design principles, they are not as readily falsifiable as scientific laws. The principles are generated inductively from prior examples of success and are subject to refinement over time as others try to adapt them to their own experiences. In this sense, they are falsifiable; if they do not yield purchase in the design process, they will be debated, altered, and eventually dropped” (p. 83).

The warrants for design principles are thus provided in this approach by the empirical studies that explore their application in new designs and contexts, and are based on the cumulative design knowledge of the community

This article focuses on the potential of the Design Principles Database to provide an alternative type warranting for DBR outcomes, based on the design principles approach described above. The type of corroboration supported by the database is based on a community endeavor, in which researchers build on each others' design knowledge, articulated as design principles, to create new designs. They explore the application of these principles in new contexts, and bring their findings back to the database. The design knowledge thus grows in the community, and principles are debated, refined, or warranted with additional field-based evidence. 


\section{The Design Principles Database}

\section{Evolution of the project}

The Design Principles Database has emerged from meetings, conversations, and collaborative activities that occurred between 2001 and 2004. The design principles project started as a grassroots movement and gradually grew to involve a substantial number of educational software designers who contributed to the development of the current form of the database. The project was initiated at a CILT (Center for Innovative Learning Technologies) conference in 2000. Participants in a Visualization and Modeling workshop requested a set of guidelines that would synthesize the knowledge in the field and enable designers to create innovative technology-based learning environments that are founded on principled design knowledge (Kali, 2002). This call resulted in a CILT seed-grant project, which subsequently organized a series of invited face-to-face and online workshops that lead to the development of the Design Principles Database. The database was intended to guide conversations in the workshops and interactive poster-sessions, to capture the library of features of technology-enhanced learning environments, to link features, empirical evidence, and theoretical underpinnings of this work, and to synthesize design knowledge at multiple levels of analysis. Today, via the NSF funded Technology Enhanced Learning in Science (TELS) center, we continue to develop the Design Principles Database and use it as a core framework to capture, synthesize, discuss and disseminate the research-based design ideas of TELS technology software innovations. 


\section{Design vocabulary}

The design principles project has stimulated the development of an emergent vocabulary to communicate design ideas. Terms used in this paper follow:

Feature is used to refer to any effort to use technology to advance learning. In particular, we use feature to describe designed artifacts, or parts of artifacts, such as modeling tools (e.g. Buckley, et al. 2004; Wu, Krajcik \& Soloway, 2001), visualizations (e.g. Dori \& Belcher, 2005; Kali \& Orion, 1997), collaboration tools (e.g. Guzdial, Rick, \& Kehoe, 2001; Ronen, Kohen-Vacs \& Raz-Fogel; in press), games (e.g., Barab et al., 2005; Shaffer, 2005), and assessment tools (e.g., Birenbaum et al., in press). The term is also used for activities designed to support the use of any of these tools. Learning environment is defined as a system that incorporates a set of these along with a navigation system and curriculum materials. Design principle is used to refer to an abstraction that connects a feature to some form of rationale. Design principles are described at several levels of specificity—articulated below.

\section{Structure of the Design Principles Database}

The Design Principles Database is a set of interconnected features and principles. Each feature is linked with a principle and principles are linked between themselves in a hierarchical manner. Principles in the database are described in three levels of generalization: Specific Principles describe the rationale behind the design of a single feature or single research investigation. Due to their direct relation to one feature, specific principles in the database are embedded within the features. Pragmatic Principles connect several Specific Principles (or several features), and MetaPrinciples capture abstract ideas represented in a cluster of Pragmatic Principles. 
Figure 1 illustrates these multiple connections schematically, and provides examples of software features and principles in the three hierarchical levels.

Insert figure 1 about here

The database includes two main modes of interaction: a Contribute mode, and a Search/Browse mode. The contribute mode enables designers to submit new features and principles to the database. To publish features in the database, authors are required to provide the following pieces of information: a) a detailed description of the functionality of the feature, b) the rationale behind the design (i.e. the specific principle), c) the context in which the feature was used, d) category, or several categories that describe the feature (e.g., visualization tools, inquiry tools, communication tools, ubiquitous computing, etc.). Finally, it is required that every feature is connected to a pragmatic principle. Once a feature is connected to a pragmatic principle, the author of the feature can edit any part of the pragmatic principle, which is usually authored by another contributor, using Wiki technology (e.g., Nicol, Littlejohn, \& Grierson, 2005). The Wiki tools enable multiple authoring, while keeping track of the principle's history to enable simple retrieval of old documentation if needed. In order to contribute a pragmatic principle, authors are required to provide a) a detailed description of the principle, b) theoretical background, and c) tips for designers including limitations, tradeoffs and pitfalls for designing with the principle. Authors are also required to connect pragmatic principles to meta-principles. There are four meta-principles, which are built into the database, and originate from the SKI (Scaffolded Knowledge Integration) framework (Linn et al., 2004). The Contribute mode thus enables the database to grow while keeping connectedness between features and principles and between principles in the different levels. It also enables the community to continually refine pragmatic 
principles. About 120 features, with their specific principles have already been contributed to the Design Principles Database from a variety of disciplines (mainly from physical, life, and earth sciences, but also from mathematics, humanities and others). About 70 of these features are in the public area, while others are in areas designated for groups, such as workshops and graduate courses or are at draft stages.

The Search/Browse mode enables users (researchers, teachers, students in the learning sciences) to search for features and principles using filters, which include any of the pieces of information described above. Navigation in the database is done via the connections between the features and three levels of principles. For instance, one might start a browsing path by using filters, to find all the features in chemistry that are based on inquiry learning for 10th grade. After choosing one of these features to review the details, she might want to link to a pragmatic principle connected to the feature, in order to better understand the overarching rationale and to read the theoretical background. Finally, she can review other features connected to this pragmatic principle, and see how it is applied in other learning environments in various contexts.

\section{Promoting DBR via the Design Principles Database: A three-phase study example}

The potential of the Design Principles Database for advancing the design field is illustrated here by analysis of a particular DBR about a peer-evaluation activity, in an undergraduate level philosophy of education course (Kali \& Ronen, 2005). The analysis of this particular study demonstrates how the researchers used the database in three stages to build on the existing body of knowledge for designing a new peerevaluation activity, and how this use eventually brought to generation of new design 
knowledge shared with the community, which strengthened the original claims.

Below is a description of the study, followed by analysis of the three phases in which the researchers used the Design Principles Database.

The peer-evaluation study, which is analyzed here to demonstrate researchers' use of the database, took place in a philosophy of education course for undergraduate level at the Technion, taught by the author of this paper. The main goal of the course was to help students develop their own perceptions about fundamental issues in education and schooling (e.g., what is the goal of schooling? What contents should be taught in school? What should be the role of the teacher?). A main theme in the course was the “ideal school” project, in which groups of 3-4 students constructed a conceptual model of a school that met their evolving educational perceptions. Toward the end of the semester each group gave a short presentation of one day in their ideal school. For this purpose, most students used PowerPoint, but other less-conventional means, such as drama-performances were also used. The presentations took place in three class meetings, with three or four presentations in each session. One challenge the instructor faced during these presentations was how to ensure that students make the most out of these meetings. Prior teaching experience in similar contexts revealed that students tend to focus on accomplishing the course's requirements (their own presentations in this case) and less interested in their peers’ projects.

This challenge was addressed by designing a peer-evaluation activity, in which students were involved in the assessment of their peers' "ideal school” presentations. The rationale for engaging students in this activity was: a) to ensure their involvement in their peers' projects, b) to create a framework for them to learn from each others' 
projects, c) to help them develop evaluation skills that they would need as future educators, and d) to reinforce criteria for designing their projects. The analysis of this peer-evaluation activity by the instructor involved the integration of hundreds of assessments (35 students, times 10 groups, times about four criteria). To help facilitate the analysis, a computerized system was used, which enabled gathering, presenting and analyzing these assessments in a productive manner. The activity was therefore performed online with CeLS (Collaborative e-Leaning Structures), a novel system that allows the instructor to create and conduct a variety of online structured collaborative activities (http://www.mycels.net) (Ronen, Kohen-Vacs, \& Raz-Fogel, in press). The sections below illustrate how this particular DBR was supported by the Design Principles Database.

\section{Methodological approach}

The current study is designed as a meta-study; it analyzes the process in which the peer-evaluation DBR study described above, shaped the design-knowledge represented in the Design Principles Database. To do this, three main phases in the researchers' use of the database in the peer-evaluation study were defined. Phase 1: Articulating design principles; Phase 2: Design-enactment-refinement iterations; Phase 3: Revising pragmatic principles. The meta-study used descriptive analysis to characterize the researchers' use of the database in these three phases. The peerevaluation study used DBR methodologies, described below.

It is important to note that the current meta-study is carried out by one of the researchers who conducted the DBR analyzed in the meta-study. In this sense, the meta-study is a reflective description of using the Design Principles Database to support the studied DBR. However, it is assumed that the involvement of the 
researcher in the DBR does not constrain the analysis. Rather, it helps in describing the details required to illustrate the potential of the database in supporting other DBR studies, and synthesizing the cumulative knowledge in the field.

\section{Phase 1: Articulating design principles}

Since the Design Principles Database is still at beginning stages, there were no design-principles articulated for peer-evaluation when the study was conducted. Therefore, it was necessary to abstract design principles from existing empirical studies in this field, and to design the first version of the peer-evaluation activity based on these principles. The literature review for articulating the pragmatic and specific principles included: Cuddy \& Oki (2001); Davies (2000); Dominick, Reilly, \& McGourty (1997); Falchikov (2003); Falchikov. \& Goldfinch (2000); Mann (1999); McConnell (2002); Miller, (2003); Ronen \& Langley (2004); Suthers, Toth, \& Weiner (1997); Topping (1998); Zariski (1996). At the end of this phase, one pragmatic principle (Figure 2) linked with three specific principles (embedded within features) were added to the database as follows (more details for each principle and feature are available at the database):

Pragmatic Principle: Enable students to give feedback to their peers

Specific Principle 1: Involve students in developing the evaluation criteria for the peer-evaluation.

Specific Principle 2: Enable anonymity to avoid bias in peer-evaluation

Specific Principle 3: Make the synthesis of the peer-evaluation results visible for learners. 
It is important to note that the rich body of knowledge concerning peer-evaluation can be translated into many more design principles. For the purpose of this study, only ideas that seemed useful for designing the peer-evaluation activity were articulated as design principles and contributed to the database.

Insert figure 2 about here

\section{Phase 2: Design-enactment-refinement iterations}

\section{Methods in the peer-evaluation study}

In order to explore the challenges of peer-evaluation in the specific context, the study was organized around three design-enactment-refinement iterations. These took place in successive semesters with a total of 144 students (Iteration 1: fall 2003 with 80 students in two groups; Iteration 2: spring 2004 with 29 students; Iteration 3: fall 2004 with 35students). Each iteration was followed by data analysis and refinements to the design of the online peer-evaluation activity. Data-sources included:

- Peer-evaluation data (numeric grades and textual justifications) gathered in the CeLS environment.

- Artifacts created by each group (PowerPoint slides of the "ideal school” project and online discussions used by each of the groups for developing the conceptions for their project).

- Students' responses to an attitude questionnaire administered at the end of the course.

- Students' spontaneous online discussions in a virtual "coffee corner" at the course’s site.

- Instructor's reflective journal including remarks about the events that took place during class. 


\section{First iteration: Initial design}

Following specific principle 1, the initial design of the peer-evaluation activity included criteria that were derived from students’ suggestions in a classroom discussion that occurred prior to the presentations and included the following: a) is the uniqueness of the school apparent? b) is the rationale clear? c) are the activities that take place in the school demonstrated clearly? The activity included an online form in which students were required to grade each of the group-presentations between 1 (poor) to 7 (excellent). The form also included text fields for students to justify their grading according to the three criteria. Students used prints of these forms to take notes during the presentations, and entered their grades and justifications to the online environment in the next few days. Following specific principles 2 and 3, at the end of the activity all students were able to view: a) a histogram of the scores for each group, b) statistical data (sample size, mean, median, and standard deviation), and c) the individual scores and the justifications for each score (presented anonymously) (figure 3). All this information was automatically generated by the CeLS environment without requiring any extra work of the instructor.

Insert figure 3 about here

In order to assess the validity of student scoring, the set of mean scores that were given by students for each of the 10 presentations was compared with the set of scores given by the instructor for these presentations. The analysis indicated that though there was a moderate positive correlation between students' scores and the instructor's scores $(\mathrm{r}=0.43)$, it was not significant $(\mathrm{p}=0.1)$. A detailed examination of the qualitative data enabled us to identify the cases in which large discrepancies were found between students and instructor's scoring. Such discrepancies were especially 
apparent in presentations that introduced educational perceptions that were relatively "extreme" according to views held by many students. Though students were specifically instructed to try to ignore personal viewpoints in their grading, it seems that they found it difficult to do so. The issue of differentiating between objective criteria and personal stands was taken as a focus for the second iteration. It is important to note that this study assumed that purely objective criteria do not exist, as we are all somewhat subjective to our personal viewpoints. However, an essential aspect of peer-evaluation is to find those criteria that will provide equitable measures that will minimize those biases.

\section{Second iteration: Differentiating between objective criteria and personal stands}

Based on the outcomes of the first iteration, and in order to foster objectivity, we decided to refine the design of the online peer-evaluation activity so that it would provide students with a way to differentiate between objective aspects of the presentation and their personal, non-objective viewpoints. Our rationale was that if students would be given a chance to express these views in a neutral area, which does not affect the score, they would be more aware of their personal values and emotional stands, and thus, provide a more objective score. Therefore, we defined the following specific principle to explore in this iteration:

Specific Principle 4: Enable students to state their personal, non-objective viewpoints about their peers' work

As in the first iteration, a class discussion about evaluation criteria preceded the activity. To engage students with the issue of personal viewpoints in peer-evaluation, 
we decided to seed the class-discussion with ideas for criteria, including a criterion about the degree to which a student is in agreement with views introduced in the presentation. Following the classroom discussion, four text fields for justifying scores were defined. The first three were similar to those defined in the first iteration (referring to uniqueness of the school, rationale, and demonstration of activities), but a forth text-field was added, named "My personal opinion about this school”. As suggested by students, ideas expressed in this field did not effect scoring. Rather, this component of the peer review was intended to provide general feedback for presenters as to the degree of acceptance of their ideas among other students. Another specific principle was defined for further exploration:

Specific Principle 5: Design features to foster discussion about non-objective evaluation criteria

Outcomes indicated that the refined design, which enabled students to express their personal viewpoints, assisted students to better differentiate between objective criteria and personal stands. This was evident from a higher correlation between the set of scores provided by the instructor for each of the groups, and those provided by students ( $r=0.62, p=0.03$ ) compared to the first iteration. Furthermore, the learning gains from the peer-evaluation activity, as indicated from the attitude questionnaire, seemed to be higher in the second iteration (figure 4). However, it was found that since the contents that are being evaluated involved cultural and political values, tensions in class-discussion between students aroused, and infiltrated as biased scoring and inappropriate and even offending justifications in the peer-evaluation 
activity (Kali \& Ronen, 2005). The issue of respecting classroom norms was thus decided as a main focus for design and exploration in the third iteration.

\section{Insert figure 4 about here \\ Third iteration: Evaluating students as evaluators}

Based on the findings of the second iteration, and in order to further foster objectivity, classroom norms, and tolerance, a third iteration of the activity was designed according to the following design principle:

Specific principle 6: When the evaluated contents are socially or culturally sensitive, avoid grading students according to peerevaluation results. Rather, evaluate students as evaluators.

According to this principle, 15\% of students’ scores in semester fall 2004 were derived from the peer-evaluation activity and indicated how well they served as evaluators. The score was comprised of: a) number of evaluations provided, b) respecting classroom pre-defined norms, c) quality of justifications, and d) degree of correlation with instructor's score. Outcomes indicated that implementation of the redesigned activity enabled students to better exploit the vast advantages of peerevaluation, tensions were decreased (Kali \& Ronen, 2005), and higher correlation with instructor ( $\mathrm{r}=0.7, \mathrm{p}=0.02$ ) were found. Furthermore, learning gains, and student satisfaction, as indicated from the attitude questionnaire stayed high. 


\section{Phase 3: Revising pragmatic principles}

After the new specific principles were added to the database, together with the example features which were explored in phase 2, the researchers of the peerevaluation study were able to enrich the original pragmatic principle (enable students to give feedback to their peers), which connects these features, with lessons learned through the cycles of the DBR. An important way to enrich a pragmatic principle in the database is to add emerging design knowledge to the section "Tips (Challenges, Limitations, Tradeoffs, Pitfalls)”. Since the knowledge gained through the particular DBR had to do with a very specific context, it was decided to articulate this knowledge as limitations of the pragmatic design principle. The limitations were stated in the database as follows:

"Note that when the contents being evaluated in a peer-evaluation activity have to do with beliefs and morals, there is higher probability for biased scoring. In such cases it is recommended to enable students to state their personal, non-objective viewpoints about their peers’ work in a neutral space,

which does not affect scoring. As in other peer-evaluation contexts this feature works best when students are involved in developing the criteria. To do that, it is recommended seed the discussion (or any other means for criteria building) with ideas for non-objective criteria.

Note also that biased scoring and inappropriate language in peer evolution can occur when the contents that are being evaluated are socio-culturally sensitive. In such cases it is advised to avoid grading students according to peerevaluation results. Rather, to reduce tensions it is recommended to evaluated 
students as evaluators, based on their respecting of classroom norms, and on the quality of their justifications.”

Another revision to the original pragmatic principle was done automatically by the system. The new features (and embedded specific principles) that were explored in this study became part of the principle in the form of links that exemplify the use of the principle and provide additional evidence and further warranting for the principle.

\section{Discussion}

The three-phase study described above illustrates a process, in which design knowledge, abstracted from the existing body of knowledge about peer-evaluation, and contributed to the Design Principles Database was explored in a new context. The design knowledge was strengthened by this exploration; the pragmatic principle "Enable students to give feedback to their peers" was successfully applied in the philosophy of education course, and thus connected with additional empirical outcomes. Furthermore, new theoretical knowledge about issues of bias and objectivity in peer-evaluation was created, brought back to the database, and synthesized with the existing knowledge. The development of this theoretical knowledge was articulated as practical design knowledge; tips for designing peerevaluation activities in which the contents being evaluated have to do with morals, values or sensitive issues.

Ideally, researchers who refine pragmatic principles based on their outcomes are not those who are the original contributors of the principles, as in the case of this research. A design study with the Design Principles Database could start when a 
researcher, or research group articulate a pragmatic design principle, which summarizes outcomes from a DBR study in a certain area. They provide theoretical background and connect the pragmatic principle with one or more features, which provide field-based evidence and illustrate how the principle was applied in their specific context (this corresponds to stage 1 in the current study, with the exception that the pragmatic principle was abstracted from the literature). Then, another research group, uses the information provided in the pragmatic principle to design new features and explore them in new contexts (this corresponds to phase 2 in the current research). Up to this stage, this is quite similar to the common process in which researchers build on knowledge published via traditional means of publication. The added value of the Design Principles Database is particularly evident in the next stage (corresponding to phase 3), in which new contributions to theory are brought back to the database and synthesized with the existing knowledge. This can be performed in two manners: a) empirical outcomes from the design iterations are explicitly translated into new features and specific principles and connected to the original pragmatic principle, and b) additional practical design knowledge, based on the research, such as limits, tradeoffs and pitfalls, are added to a pragmatic principle, and c) the pragmatic principle is refined, using the Wiki capabilities of the database, to capture the new design knowledge gained in the research.

\section{Conclusions}

The analysis above indicates that the Design Principles Database can contribute to the development of theory on one hand, and to design practice on the other. Theory is developed through continuous empirical reexamination, negotiation and refinement of 
pragmatic design principles by the community. At the same time these principles become more useful for designers (and thus better deserve their name) when they are connected with a variety of features and specific principles, which exemplify how they can be applied for different contexts.

At the beginning of this article, methodological challenges in DBR, expressed by several researchers such as Kelly (2004) and Shavelson et al. (2003) were stated. These authors were concerned that due to the contextual nature of DBR, methodologies usually refrain from experimental controls. Thus, they questioned the capability of DBR methodologies in generalizing findings and in warranting claims. The current study suggests that the process of synthesizing design knowledge via the Design Principles Database can move DBR towards meeting these challenges. This process maintains the naturalistic methodologies required in order to gain a deep understanding about the effect of technology on various aspects of learning. Yet it also enables reexamination of the outcomes, articulated as design principles, by different researchers, in other settings. It is argued here that this process, supported by the Design Principles Database, can serve as a productive approach for advancing DBR.

Nonetheless, the Design Principles Database is still in its initial stages, and its framework is open for public negotiation and refinement. There are other research teams that have suggested frameworks for connecting between elements of design and generalized design guidelines. One important endeavor in this direction is the Scaffolding Design Framework for designing educational software suggested by a group from the University of Michigan and Northwestern University (Quintana et. al, 
2004). Another important venture in this direction is the Design Patterns trajectory (Linn \& Eylon, in press), which seeks to identify common factors in promising sequences of activities and define them as patterns that can guide designers of learning environments. Advances to merge efforts between these projects are currently taking place.

Additionally, in order to exhaust the full potential of the Design Principles Database there is a need for a critical mass of contents contributed and negotiated by the community. As Collins et al. (2004) state:

"Our approach to design research requires much more effort than any one human can carry out. We put forward these ideas not because we expect each and every design experiment to embody them, but to give an overview of all the things the design-research community is responsible for. In our ideal world, design research will move in the direction of embodying many of the practices we outline here. But it will take teams of researchers and accessible archives documenting design experiments... to make these dreams at all possible. (p. 33)

We envision this dream come true when the Design Principles Database will be populated with hundreds of features and specific principles, connected to pragmatic principles, which continuously evolve through negotiation of a dynamic knowledgebuilding community. To meet this challenge, TELS (Technology Enhanced Learning in Science) center, continues to organize workshops and graduate courses that support researchers in contributing features and principles to the database. Additionally, we 
encourage readers who are involved in DBR to take part in this endeavor and share their design knowledge with the community of the Design Principles Database.

\section{Acknowledgements}

The DATABASE is supported by the US National Science Foundation as part of the TELS center (grant ESI/CLT 0334199). I would like to thank Marcia Linn, TELS Principle Investigator, for her enormous inspiration, support and contribution to the Design Principles Database project. I would also like to thank the CILT (Center for Innovative Learning Technologies) postdocs and PIs, who supported and encouraged the design principles project at its early stages.

Many thanks to Miky Ronen from the Holon academic institute of technology, for providing the CeLS environment and helping with the peer-evaluation analysis, to Orit Parnafes from the University of California, Berkeley, and to the design-group graduate students at the Technion, for very thoughtful comments on drafts of this paper.

Finally, thanks to all the people who helped shape the framework, and contributed features and principles to the Design Principles Database. 


\section{References}

Alexander, C., Ishikawa, S., \& Silverstein, M. (1977). A pattern language: Towns, buildings, and construction. New York: Oxford University Press.

Barab, S. A., \& Squire, K. D. (2004). Design-based research: Putting our stake in the ground. The Journal of the Learning Sciences, 13(1), 1-14.

Barab, S. A., Thomas, M, Dodge, T., Carteaux, R., and Tuzun, H. (2005). Making learning fun: Quest Atlantis, a game without guns. Educational Technology Research and Development, 53(1), 86-107.

Bell. P., Hoadley, C.M., \& Linn, M.C., (2004). Design-based research in education. In Linn, M.C., Davis, E.A., \& Bell, P. (Eds), Internet environments for science education (pp. 73-85). Lawrence Erlbaum Associates.

Birenbaum, M., Breuer, K., Cascallar, E., Dochy F., Dori, Y., Ridgway J., \& Wiesemes R. (2006 March/April.). A learning integrated assessment system. In: EARLI Series of Position Papers. R. Wiesemes, G. Nickmans A. (Eds.) To appear in Educational Research Review.

Buckley, B.C., Gobert, J.D., Kindfield, A., Horwitz, P., Tinker, R., Gerlits, B., Wilensky, U., Dede, C., \& Willett, J. (2004). Model-based Teaching and Learning with BioLogica $^{\mathrm{TM}}$ : What do they learn? How do they learn? How do we know? Journal of Science Education and Technology. 13(1), 23-41.

Collins, A. (1992). Toward a design science of education. In E. Scanlon \& T. O'Shea (Eds.), New directions in educational technology. Berlin: Springer-Verlag, 1992.

Collins, A., Joseph, D., \& Bielaczyc, K. (2004). Design research: Theoretical and methodological issues. Journal of the Learning Sciences, 13(1), 15-42.

Cuddy, P., J., \& Oki, (2001). Online peer-evaluation in basic pharmacology. Academic medicine, 76(5): 532-3.

Davies, P. (2000). Computerized peer assessment. Innovations in Education \& Training International, 37(4), 346-355.

Dede, C. (2005). Why design-based research is both important and difficult. Educational Technology, 45 (1), 5-8.

Dominick P. G., Reilly, R. R., \& McGourty J. (1997). The effects of peer feedback on team member behavior. Group and Organization Management, 22, 508-520.

Dori, Y.J., \& Belcher, J.W., (2005). How does technology-enabled active learning affect students' understanding of scientific concepts? The Journal of the Learning Sciences, 14(2), 243-279.

Falchikov, N. (2003). Involving Student in Assessment. Psychology Learning and Teaching, 3(2), 102-108. 
Falchikov, N., \& Goldfinch, J. (2000). Student Peer Assessment in Higher Education: A meta-analysis comparing peer and teacher marks. Review of Educational Research. 70 (3), 287-322.

Gamma, E., Helm, R., Johnson, R., \& Vlissides, J. (1995). Design patterns: Elements of reusable object-oriented software. Reading, MA: Addison-Wesley Longman, Inc.

Guzdial, M., Rick, J., \& Kehoe, C.(2001) Beyond Adoption to Invention: TeacherCreated Collaborative Activities in Higher Education, Journal of the Learning Sciences, 10 (3), 265-279.

Kali, Y. (2002). CILT2000: Visualization and Modeling. Journal of Science Education and Technology, 11(3), 305-310.

Kali, Y. (in press). Collaborative knowledge-building using the Design Principles Database. To appear in the International Journal of Computer Support for Collaborative Learning.

Kali, Y., and Orion, N. (1997). Software for assisting high school students in the spatial perception of geological structures. Journal of Geoscience Education. 45, $10-21$.

Kali, Y., \& Ronen, M. (2005). Design principles for online peer-evaluation: Fostering objectivity. Proceedings of CSCL 2005 (Taipei, Taiwan). In Koschmann, T., Suthers, D.D. \& Chan, T.W. (Eds), Computer support for collaborative learning: The Next 10 Years! Lawrence Erlbaum Associates.

Kelly, A.E. (2004). Design research in education: Yes, but is it methodological? Journal of the Learning Sciences, 13(1), 115-128.

Linn, M.C., Bell, P., \& Davis, E.A., (2004). Specific design principles: Elaborating the scaffolded knowledge integration framework. In Linn, M.C., Davis, E.A., \& Bell, P. (Eds), Internet environments for science education. Lawrence Erlbaum Associates.

Linn, M. C., \& Eylon, B.-S. (in press). Science Education: Integrating Views of Learning and Instruction. In P. A. Alexander \& P. H. Winne (Eds.), Handbook of Educational Psychology (2nd ed.). Mahwah, NJ: Lawrence Erlbaum Associates.

Mann, B. (1999). Web course management "Post and vote": Peer assessment using generic Web tools. Australian Educational Computing, 14(1).

McConnell, D. (2002). Collaborative assessment as a learning event in Elearning environments. Proceedings of CSCL 2002 (2002, Boulder, CO). In G. Stahl (Ed), Computer support for collaborative learning: Foundations for a CSCL community. Hillsdale, NY: Lawrence Erlbaum Associates.

Miller, P. J. (2003). The effect of scoring criteria specificity on peer and selfassessment. Assessment \& Evaluation in Higher Education, 28(4), 383 - 394. 
Nicol, D., Littlejohn, A, \& Grierson, H. (2005). The Importance of Structuring Information and Resources within Shared Workspaces during Collaborative Design Learning. Open Learning, 20(1), 31-49.

Quintana, C., Reiser, B.J., Davis, E.A., Krajcik, J., Fretz, E., Golan-Duncan R., et al. (2004). A scaffolding design framework for software to support science inquiry, Journal of the Learning Sciences, 13(3), 337-386.

Ronen, M., \& Langley, D. (2004). Scaffolding complex tasks by open online submission: Emerging patterns and profiles. Journal of Asynchronous Learning Networks, 8(4), 39-61.

Ronen, M., Kohen-Vacs, D., \& Raz-Fogel, N. (in press), Adopt \& Adapt: Structuring, Sharing and Reusing Asynchronous Collaborative Pedagogy. To appear in Proceedings of CSCL 2006 (Bloomington IN).

Shaffer, D. W. (2005). Epistemic Games. Innovate, 1(6). Reprinted in Computer Education (in press).

Shavelson, R. J., Phillips, D.C., Towne, L., \& Feuer, M.J. (2003). On the science of education design studies. Educational Researcher, 32(1), 25-28.

Simon, H. A. (1969). The sciences of the artificial. Cambridge, MA: MIT Press.

Suthers. D.D., Toth, E.E., \& Weiner, A. (1997). An integrated approach to implementing collaborative inquiry in the Classroom. Proceedings of CSCL 1997 (Toronto, Ontario). In Hall, R., Miyake, N., \& Enydey, N. (Eds.), The second international conference on Computer Support for Collaborative learning (pp. 272-279).

The Design-Based Research Collective, (2003). Design-based research: An emerging paradigm for educational inquiry. Educational Researcher, 32 (1), 5-8.

Topping, K. (1998). Peer assessment between students in colleges and universities, Review of Educational Research, 68(3), 249-276.

Tufte, E. R. (1983). The visual display of quantitative information. Cheshire, CT: Graphics Press.

Wu, H. K., Krajcik, J., \& Soloway, E. (2001). Promoting understanding of chemical representations: Students'use of a visualization tool in the classroom. Journal of Research in Science Teaching, 38, 821 - 842.

Zariski, A. (1996). Student peer assessment in tertiary education: Promise, perils and practice. Proceedings of the 5th Annual Teaching Learning Forum, (Perth: Murdoch). In Abbott, J. and Willcoxson, L. (Eds), Teaching and learning within and across disciplines (pp.189-200). Perth: Murdoch. 
Figure 1: Schematic representation of structure of the Design Principles Database

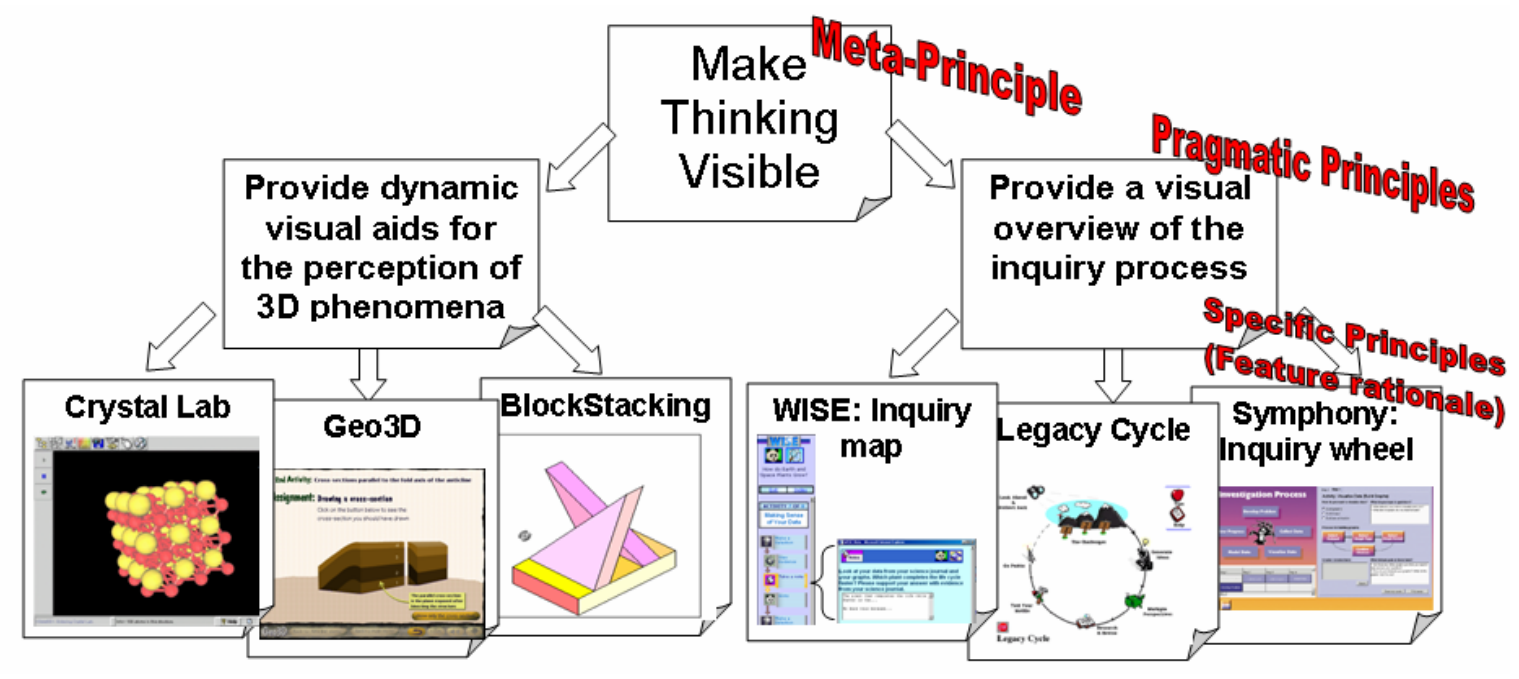


Figure 2: Pragmatic principle in the Design Principles Database

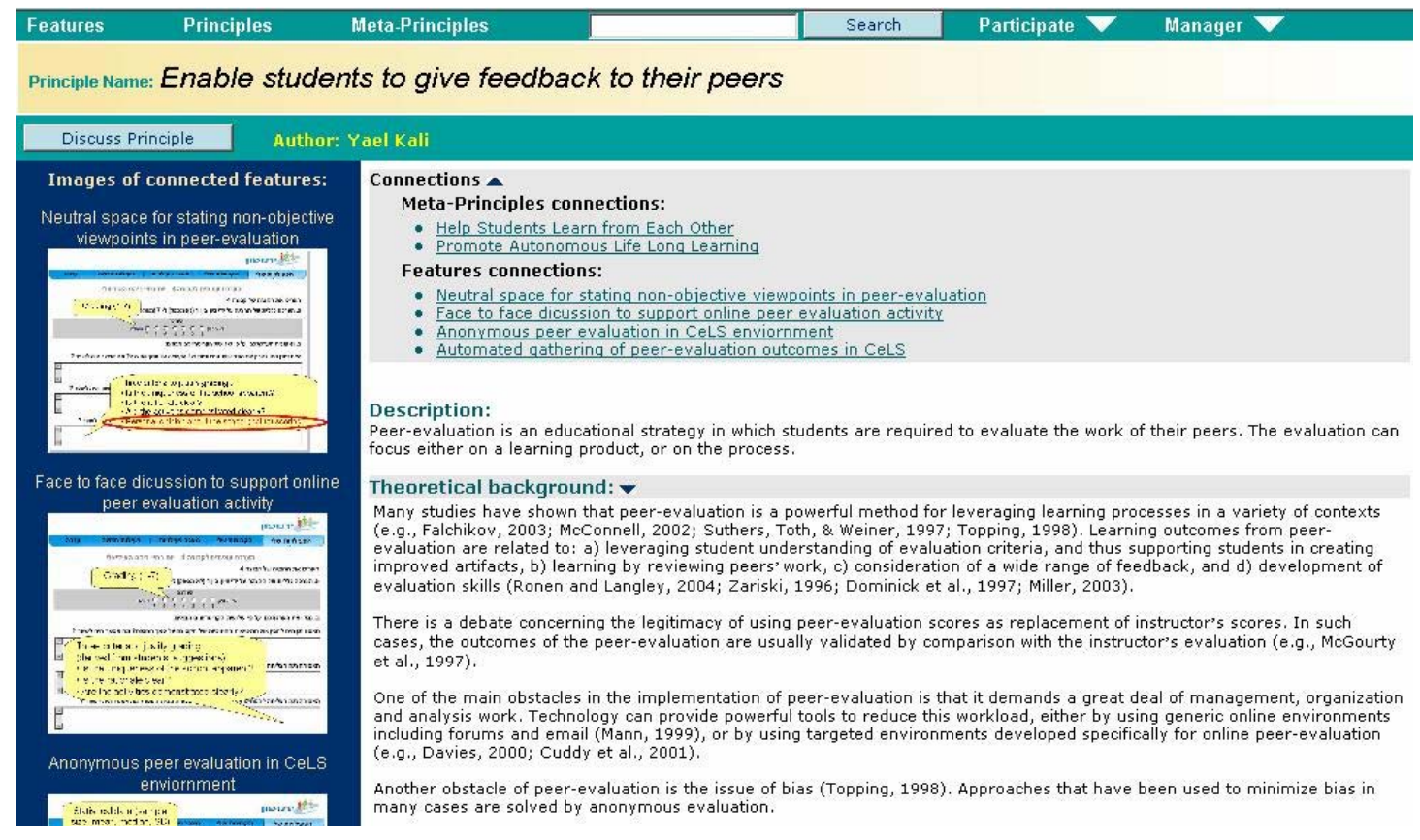


Figure 3: Interface of the peer-evaluation activity in the CeLS environment

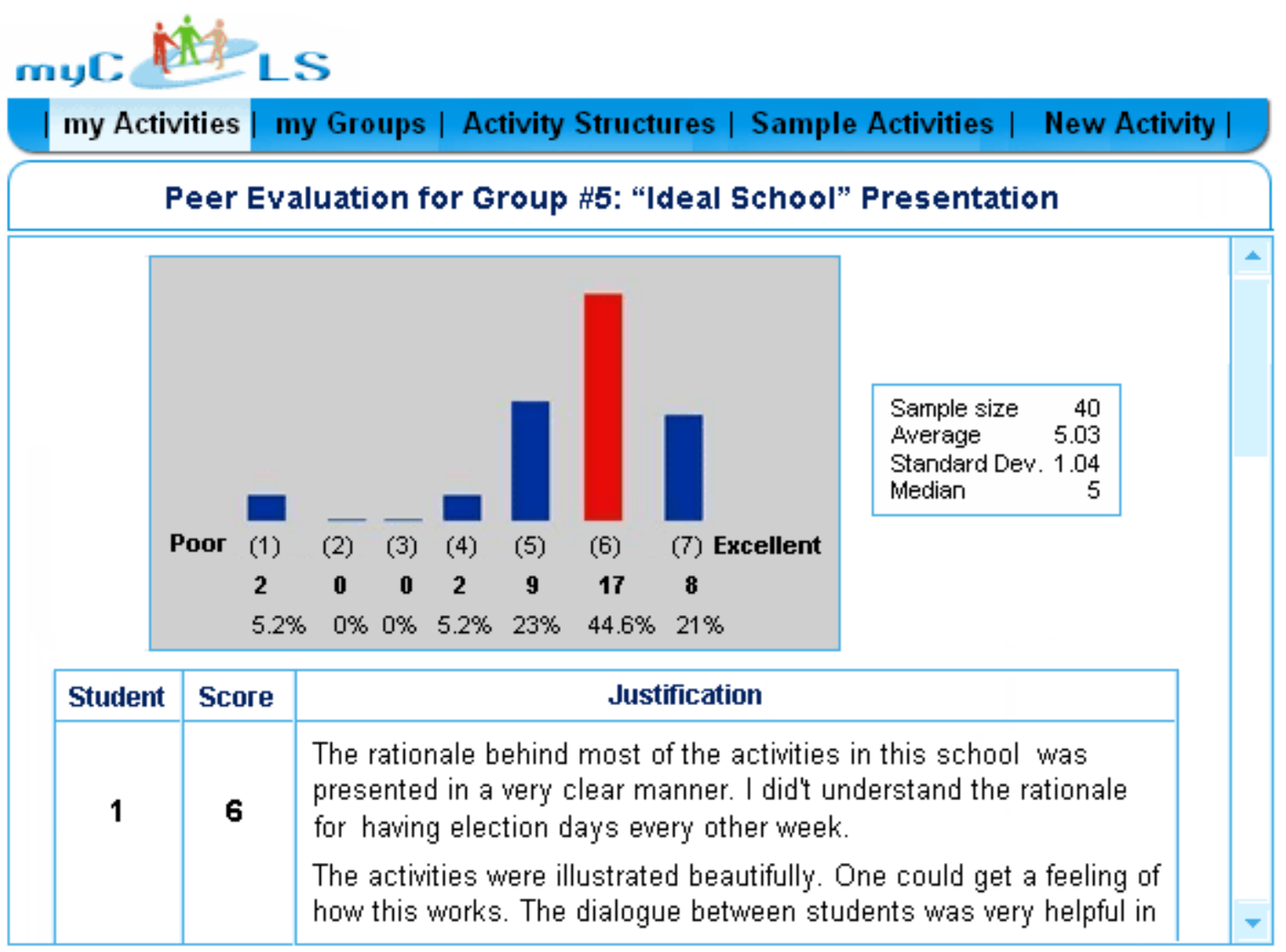


Figure 4: The degree of contribution of the peer-evaluation activity on student learning in the first two iterations as indicated from the attitude questionnaire

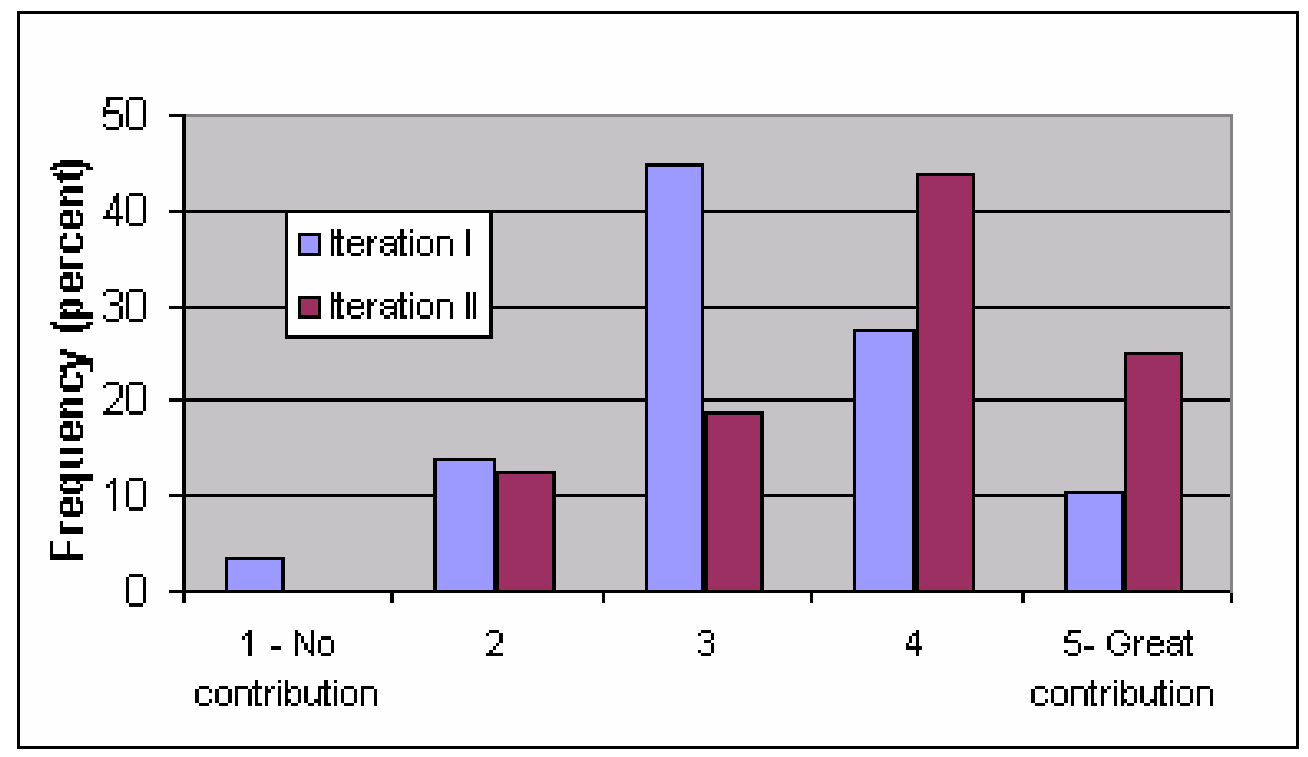

